\title{
Synthesis of Mesostructured or Mesoporous Aluminas in the Presence of Surfactants. Comprehension of the Mechanisms of Formation
}

\author{
L. Sicard' ', B. Lebeau' ' J. Patarin' ' and F. Kolenda' \\ 1 LMM (UMR CNRS-7016, CNRS), ENSCMU, Université de Haute-Alsace, 3, rue A.-Werner, 68093 Mulhouse - France \\ 2 Institut français du pétrole, BP 3, 69390 Vernaison - France \\ e-mails: lorette.sicard@wanadoo.fr - b.lebeau@uha.fr - j.patarin@uha.fr - frederic.kolenda@ifp.fr
}

\begin{abstract}
Résumé - Synthèse d'alumines mésostructurées et mésoporeuses en présence de tensioactifs. Compréhension des mécanismes de formation - Ce travail présentait un double objectif : la synthèse d'alumines mésoporeuses en milieu aqueux et la compréhension des mécanismes de formation. Des alumines mésoporeuses ont été obtenues à partir d'une solution acide de polycation de Keggin d'aluminium et d'une micelle mixte de palmitate de sodium et de bromure de cétyltriméthylammonium. Le diamètre des pores a pu être augmenté en élevant le $\mathrm{pH}$ final. La synthèse d'alumines a également été réalisée à partir d'une solution basique d'aluminate de sodium. Des volumes poreux et des surfaces spécifiques très importants ont été obtenus par lavage du précipité à l'éthanol ou à l'acétone et non à l'eau. Une étude fondamentale de compréhension du mécanisme de formation d'une alumine mésostructurée, de symétrie hexagonale, a également été menée pour améliorer les modes opératoires. L'étude des interactions entre tensioactif et charpente aluminique nous a permis d'expliquer pourquoi la structure s'effondre lors de la calcination. Un mécanisme de formation, basé sur des observations de fluorescence, est également présenté. Il a été établi que les espèces aluminiques interagissent avec les micelles et polymérisent à leur surface. Cependant, les micelles sont quasi sphériques tout au long de l'expérience et ne se réorganisent pas selon une symétrie hexagonale avant l'apparition d'un précipité.
\end{abstract}

\footnotetext{
Abstract - Synthesis of Mesostructured or Mesoporous Aluminas in the Presence of Surfactants. Comprehension of the Mechanisms of Formation - The aim of the present study was double: the synthesis of mesoporous aluminas in aqueous medium and the comprehension of their mechanisms of formation. Mesoporous aluminas were obtained from an acidic solution of the aluminum Keggin polycation and a mixed micelle of sodium palmitate and cetyltrimethylammonium bromide. The pore diameters could be increased by increasing the final $\mathrm{pH}$. Aluminas were also obtained from a basic solution of sodium aluminate. Very important pore volumes and specific surface areas were obtained when washing with ethanol or acetone instead of water. A fundamental study to understand the mechanism of formation of a mesostructured alumina, whose symmetry was hexagonal, was also carried out in order to improve the procedures. The study of the interactions between the surfactant and the alumina framework allowed us to explain why the structure collapses upon calcination. A mechanism of formation, based on fluorescence observations, is also presented. It was established that the aluminum species interact with the micelles and polymerize within the palisade layer. However, the micelles are quasi spherical throughout the experiment and do not organize into a hexagonal array before a precipitate is observed.
} 


\section{INTRODUCTION}

Aluminas constitute a vast family of powders whose specific properties, such as the crystalline structure, the porous texture or the surface activity can be tailored through a good understanding of the effect of the preparation variables on the solid properties.

Adsorption and catalysis remain big consumers of transition aluminas ( $\gamma$ or $\eta$ alumina) derived from the thermal treatment of aluminum trihydroxide such as gibbsite or from aluminium oxy-hydroxides such as boehmite gels.

Industrial applications of thermally activated aluminas can be classified into three categories $[1,2]$ :

- Aluminas used solely: illustrations can be found in the Claus catalysis for the conversion of hydrogen sulfide into sulfur, in the drying of gases or in the selective adsorption of ions in liquid purification.

- Aluminas used as inert catalytic support: the hydrotreatments of hydrocarbon residues (hydrodemetallation, hydrodesulfurization and hydrodenitrification) require aluminas with high pore volume and specific distribution of pore sizes.

- Aluminas used as active carrier: adding promoters to the formulation can boost some specific properties. As illustrations, the alumina surface acidity is adjusted by adding small amounts of chloride (formulation of the reforming catalyst) or the thermal stability of the alumina surface is increased by incorporating small amounts of silica or rare earth metals (preparation of catalyst for the automotive exhaust gas treatment).

In most cases, $\gamma$-alumina supports, whose surface area is typically in the range of 180 to $250 \mathrm{~m}^{2} / \mathrm{g}$, are preferred. These carriers display pore sizes between 60 to $150 \AA$ with cumulative pore volume between 0.5 to $0.7 \mathrm{~cm}^{3} / \mathrm{g}$. Large volumes are associated with bimodal porosity. Larger pores may range from a few hundred to a few thousand angstroms in size.

These applications are operated under severe conditions: temperatures ranging from 350 to $600^{\circ} \mathrm{C}$, pressure rising up to 200 bar. The technology associated with these conditions requires other properties from alumina particles such as mechanical strength, adequate shape and dimensions. Here again, alumina precursors such as boehmite gels offer a good ability for agglomeration and shaping with conventional techniques (extrusion, bead forming or pelletization). As a result, alumina hydrates are commonly used as binders to agglomerate other oxides such as zeolites.

The final choice of an alumina is the result of a complex optimization procedure of several properties with regards to the catalytic operating constraints and the economics of the whole process. A lot of research has been devoted to the control of alumina properties such as the structure, the pore texture or the surface activity at various stages of the manufacturing process: the precursor synthesis and purification, the thermal activation and the impregnation of metals.

In this paper, we concentrate on a novel route for preparing inorganic mesoporous powders with highly structured porous network. Organized mesoporous materials present a regular arrangement of pores as well as high pore volumes and specific surface areas. The mean pore diameter is superior to $2 \mathrm{~nm}$. Consequently, they can be used for catalysis or separation which require huge molecules. They are synthesized in the presence of surfactants, molecules able to form, in solution, aggregates named micelles. The first syntheses concerned silica-based solids before extending to other oxides such as aluminas. Indeed, organized mesoporous aluminas would be of great interest as catalytic supports if the gain concerning their properties compensates the increase in production costs.

The first syntheses of mesostructured aluminas reported in the literature were made by Huo et al. [3, 4] in the presence of mono $n$-dodecylphosphate or sodium dodecylbenzene sulfonate (SDBS). However, the structure of these materials was lamellar. The majority of the other syntheses carried out in the presence of anionic surfactants led to disordered structures (presence of a broad single diffraction peak at $2 \theta<10^{\circ}$ ). For example, Vaudry et al. [5] used SDBS and fatty acids with aluminum alkoxides in formamide and alcoholic media, respectively. A diffraction peak was still visible after calcination at $430^{\circ} \mathrm{C}$ and the materials presented specific surface areas ranging between 500 and $700 \mathrm{~m}^{2} \cdot \mathrm{g}^{-1}$ and a mean pore diameter of about $2 \mathrm{~nm}$. Liu et al. [6] succeeded in adjusting the pore size of mesoporous aluminas between 3.3 and $4.2 \mathrm{~nm}$ by varying the concentration of dibenzoyl-L-tartaric acid in an alcoholic medium, with the aluminum sec-butoxyde as the inorganic source. Valange et $a l$. [7] also synthesized a material with a disordered structure using sodium dodecyl sulfate (SDS) in an aqueous medium. It is noteworthy that the same authors, using fatty acids or mixed micelles composed of sodium palmitate and cetyltrimethylammonium bromide (CTAB), obtained lamellar structures. However, the presence of a diffraction peak after calcination at $450^{\circ} \mathrm{C}$, the high specific surface area $\left(707 \mathrm{~m}^{2} \cdot \mathrm{g}^{-1}\right.$ for $\left.\mathrm{pH}=5\right)$ and the pore volume $\left(0.3 \mathrm{~cm}^{3} \cdot \mathrm{g}^{-1}\right)$ of this material suggested rippled sheets rather than independent sheets. Finally, using aqueous SDS, Stein et al. [8] and Holland et al. [9] synthesized a nonlamellar alumina whose structure was not elucidated. On the other hand, Yada et al. [10-11] synthesized a hexagonal alumina in the presence of the same aqueous surfactant (SDS) by varying the $\mathrm{pH}$ by the thermal decomposition of urea. This last material is the only mesostructured alumina with a hexagonal structure reported so far. However, the calcination of the material led to a collapse of the structure. The sulfate head groups of the surfactants appear to be too embedded within the inorganic walls. This would result in sintering upon calcination. Yada et al. [12,13] showed that the addition of yttrium with a 
molar ratio $\mathrm{Y} / \mathrm{Al}=0.18$ in the final product stabilized the structure and allowed the extraction of the surfactant with sodium acetate without altering the structure. They also showed $[10,11]$ that the material that precipitates first has a lamellar structure and that a structural transition occurs between $\mathrm{pH}=6$ to 7 . This transition can be inhibited by co-incorporation of long chain alcohols or didodecyldimethylammonium bromide [14]. Finally, a wide variety of morphologies can be obtained by varying the urea concentration [15].

Other studies reported syntheses of mesostructured aluminas realized in the presence of alkyltrimethylammonium surfactants. They also led to disordered structures. Acosta et al. [16] worked with aluminum chloride and obtained materials with specific surface areas of about $480 \mathrm{~m}^{2} \cdot \mathrm{g}^{-1}$ and pore diameters adjustable from 2.9 to $5.5 \mathrm{~nm}$. Cabrera et al. $[17,18]$ used a complex made of aluminum sec-butoxyde and triethanolamine (TEA). The materials showed adjustable pore diameter in the range from 3.3 to $6.0 \mathrm{~nm}$ depending on the water/TEA concentration ratio.

Nonionic surfactants were also used for the synthesis of mesotructured aluminas and led to disordered structures, as in the case of mesoporous silica. In 1996, Bagshaw et al. [19] explored the $\mathrm{N}^{0} \mathrm{I}^{0}$ pathway where $\mathrm{N}^{0}$ is a poly(ethylene oxide) based surfactant and $\mathrm{I}^{0}$ is the alumina framework. They obtained, in an hydroalcoholic medium from aluminum alkoxides, materials with specific surface areas ranging from 420 to $535 \mathrm{~m}^{2} \cdot \mathrm{g}^{-1}$ and mean pore diameters from 2.4 to $4.7 \mathrm{~nm}$ after calcination at $500^{\circ} \mathrm{C}$. The thermal stability of these materials could be improved by incorporation of cerium or lanthanide ions [20] with, for example, an increase in specific surface area of 35\%. More recently, Yang et al. [21] also succeeded in synthesizing a material with a specific surface area of $300 \mathrm{~m}^{2} \cdot \mathrm{g}^{-1}$ and a mean pore diameter of $14 \mathrm{~nm}$ using a triblock copolymer and a cheap aluminum source, aluminum chloride. The chemical analyses indicated the incorporation of chloride in the inorganic framework. Valange et al. [7] showed the possibility of synthesizing a mesoporous alumina in an aqueous medium in the presence of N-N-dimethyldodecylamine-N-oxide. Finally, Neeraj et al. [22] explored the $S^{0} \mathrm{I}^{0}$ pathway in an ethanolic medium using aluminum alkoxides and long chain amines $\left(\mathrm{I}^{0}\right)$. The material, after washing with acetone, could present a textural mesoporosity. Its specific surface area was found to be $400 \mathrm{~m}^{2} \cdot \mathrm{g}^{-1}$ with an average pore diameter close to $3 \mathrm{~nm}$.

The investigations upon the mechanisms of formation of ordered mesoporous materials were mostly carried out on silica-based materials. The first one was reported by Beck et al. [23] and referred to as "liquid crystal templating" (LCT). Two ways of formation were proposed: on the one hand a preformation of a hexagonal array of rod-like micelles followed by their impregnation by silicate species which led to the precipitation of a MCM-41 material or, on the other hand, the impregnation of rod-like micelles that assemble only afterwards into a hexagonal structure. However, the micelles do not always form a hexagonal structure at the surfactant concentration used so only the second pathway was retained. A main progress was made by Firouzi et al. [24] who proposed a cooperative organization of the organic and inorganic species driven by the electrostatic interactions between the cationic surfactant micelles $\left(\mathrm{S}^{+}\right)$and the inorganic framework $\left(\mathrm{I}^{-}\right)$. The key step would be an exchange of the initial counterions of the spherical or cylindrical micelles with the silicate species. The polymerization of the latter would lead to a rearrangement of the array into a hexagonal structure. However, the occurrence of such an ionic exchange at the micelle surface was not supported by the results of a recent study of the precursor solutions of MCM-41 materials by fluorescence probing methods [25]. Indeed, this study showed no micelle growth, the micelle shape remaining quasi spherical until the precipitation of the mesoporous silica occurred, and very little exchange of the micelle-bound bromide counterions by the silicate species at the micelle surface. In view of these results, different mechanisms seem to occur, depending on the synthesis conditions.

In a first time, we aimed at synthesizing mesoporous aluminas in the presence of surfactants. Two systems were explored. On the one hand, an acidic precursor solution of the aluminum Keggin polycation $\left(\mathrm{Al}_{13}\right)$ was used. The micelles, negatively charged, were composed of 80 molar $\%$ of sodium palmitate and $20 \%$ of cetyltrimetylammonium bromide (CTMABr). On the other hand, an original method was tried, using sodium aluminate as the inorganic source and micelles, positively charged, composed of 80 molar $\%$ of CTMABr and $20 \%$ of sodium palmitate. In a second time, we studied the nature of the interactions between the surfactant and the inorganic framework within a mesostructured alumina and the mechanism of formation of such a material [26-28]. The system already published in the literature by Yada et al. [10, 11] was chosen for this study because it was the only alumina described which presents a hexagonal symmetry and because the precipitation was obtained by a progressive increase of the $\mathrm{pH}$ by decomposition of urea.

\section{EXPERIMENTAL SECTION}

\subsection{Reactants}

Three different aluminum sources were used: aluminum chloride hexahydrate (Fluka, 99\%), aluminum nitrate nonahydrate (Fluka, 98\%) and sodium aluminate (Riedel de Haën, 92\%). The different surfactants-cetyltrimethylammonium bromide (98\%), sodium palmitate $(98 \%)$ and sodium dodecyl sulfate (98\%)—were purchased from Fluka. Finally, three $\mathrm{pH}$ modifiers were also used: sodium 
hydroxide platelets (Fluka, 98\%), a $1 \mathrm{~mol} \cdot \mathrm{l}^{-1}$ hydrochloric acid solution (Titrisol ${ }^{\circledR}$, Merck$)^{2}$ and urea (Prolabo, 99.5\%).

\subsection{Synthesis Procedures}

\subsubsection{Synthesis Procedure from an Acidic Precursor Solution ( $\mathrm{Al}_{13}$, Way $\left.\mathrm{A}\right)$}

The inorganic precursor, an $\mathrm{Al}_{13}$ solution, was prepared by dissolving $20 \mathrm{mmol}(4.83 \mathrm{~g})$ of aluminum chloride hexahydrate $\left(\mathrm{AlCl}_{3} \cdot 6 \mathrm{H}_{2} \mathrm{O}\right)$ in $100 \mathrm{ml}$ of deionized water. $90 \mathrm{ml}$ of a $0.55 \mathrm{~mol} \cdot \mathrm{l}^{-1}$ sodium hydroxide solution was added dropwise under vigorous stirring. The $\mathrm{pH}$ of the resulting solution was equal to 5 . The solution of surfactants was made by dissolving $2.23 \mathrm{~g}(7.7 \mathrm{mmol})$ of sodium palmitate and $0.73 \mathrm{~g}(2.0 \mathrm{mmol})$ of CTMABr in $80 \mathrm{ml}$ water. The desired $\mathrm{pH}$ was reached by adding a $20 \mathrm{~g} \cdot \mathrm{l}^{-1}$ sodium hydroxide solution.

The three solutions mentioned previously were heated at $50^{\circ} \mathrm{C}$. Two addition orders, giving similar materials were tried: either the surfactants and the sodium hydroxide solutions were simultaneously added to the $\mathrm{Al}_{13}$ solution, either the surfactants and the $\mathrm{Al}_{13}$ solutions were mixed together before adding sodium hydroxide. A precipitate formed as soon as the three solutions are mixed. The suspension was allowed to stand one night at room temperature. The solid (referred to as sample A) was then recovered by filtration and washed extensively with hot water several times to eliminate the nonincorporated surfactant.

\subsubsection{Synthesis Procedure from a Basic Precursor Solution (Way B)}

In this synthesis, all the solutions were also heated at $50^{\circ} \mathrm{C}$. The solution of surfactants was made by adding, under vigorous stirring, $0.58 \mathrm{~g}(2 \mathrm{mmol})$ of sodium palmitate solubilized in $25 \mathrm{ml}$ of water to a beaker containing $2.97 \mathrm{~g}$ ( $8 \mathrm{mmol}$ ) of CTMABr in $15 \mathrm{ml}$ of water. The inorganic precursor, prepared by dissolving $1.96 \mathrm{~g}(22 \mathrm{mmol})$ of sodium aluminate in $10 \mathrm{ml}$ of water, was added to the beaker. A precipitate was then obtained by adding $22 \mathrm{ml}$ of a $1 \mathrm{~mol} \cdot \mathrm{l}^{-1}$ hydrochloric acid solution. The mixture was then left $15 \mathrm{~min}$ at $50^{\circ} \mathrm{C}$ under vigorous stirring before recovering and washing the solid (named sample B) with water by centrifugation.

\subsubsection{Synthesis Procedure for the Synthesis of a Hexagonally Mesostructured Alumina by a Progressive Increase of the $\mathrm{pH}$}

The precursor solution was made by dissolving $7.6 \mathrm{~g}$ $(20 \mathrm{mmol})$ of aluminum nitrate nonahydrate, $11.9 \mathrm{~g}$ (40 mmol) of SDS and $36.2 \mathrm{~g}$ (600 mmol of urea) in $21.6 \mathrm{~g}$ of deionized water at $40^{\circ} \mathrm{C}$. The $\mathrm{pH}$ was slowly increased by decomposing urea at $80^{\circ} \mathrm{C}$ (or $60^{\circ} \mathrm{C}$ for fluorescence experiments). When the desired $\mathrm{pH}$ was reached, the solution was cooled down and the product was recovered and washed with hot water by filtration.

\subsection{Characterization Techniques}

The powder X-ray diffraction (XRD) patterns were obtained with $\mathrm{Cu}-\mathrm{K}_{\alpha 1}$ radiation on a STOE STADI-P diffractometer equipped with a curved germanium (111) primary monochromator and a linear position-sensitive detector. Typically, the diffractograms were collected at angles $2 \theta$ between 1 and $10^{\circ}$.

Scanning electron microscopy (SEM) experiments were realized at the LMM on a Philips XL 30 and at IFP on a JEOL $6340 \mathrm{~F}$. Transmission electron microscopy (TEM) was made at IFP on a JEOL $100 \mathrm{CX}$ or a JEOL $120 \mathrm{CX}$.

The nitrogen adsorption and desorption isotherms of the calcined samples were determined at $-196^{\circ} \mathrm{C}$ on a Micromeritics ASAP 2010 apparatus. Prior to the measurements, the samples were outgassed first at $90^{\circ} \mathrm{C}$ during $1 \mathrm{~h}$ and then at $350^{\circ} \mathrm{C}$ for $16 \mathrm{~h}$. The equivalent surface areas were calculated using the BET (Brunauer, Emmet, Teller) equation [29].

Sample controlled thermal analysis (SCTA) was carried out on a home-made apparatus under a constant residual pressure of $5.10^{-3}$ mbar [30]. The totality of the evolved gases was analyzed in situ via a mass spectrometer ( $V G$ Quadrupoles) with a maximum detection of $m / z=100$.

Fluorescence techniques were used to study micelles in clear solutions. In all the experiments described in this paper, pyrene was used as the probe molecule. The pyrene fluorescence lifetime, $\tau$, was determined by time-resolved fluorescence quenching, recording the fluorescence decay curves on a single photon counting apparatus. Micelle aggregation numbers $(N)$, which is the number of surfactant molecules per micelle, were determined in the presence of dodecyl pyridinium chloride as fluorescence quencher [31].

\section{SYNTHESIS OF MESOPOROUS ALUMINAS}

Two ways of preparing mesoporous aluminas are presented, one from an acidic precursor solution (way A), the other one from a basic precursor solution (way B). In the first case, we chose to use a solution of the polycation of Keggin $\left[\mathrm{Al}_{13} \mathrm{O}_{4}(\mathrm{OH})_{24}\left(\mathrm{OH}_{2}\right) 12\right]^{7+}$, which will be referred to as $\mathrm{Al}_{13}$. This source presents several advantages: the $\mathrm{Al}_{13}$ molecules constitute a preformed building unit. Moreover, the $\mathrm{pH}$ of the solution is as high as 4-5. This avoids the formation of the oligomers observed when increasing the $\mathrm{pH}$ of a solution of monomeric aluminum species ( $\mathrm{pH}$ close to 3 ). Finally, Valange et al. [7] observed that the pore diameter distribution is narrower in the case of aluminas synthesized from an $\mathrm{Al}_{13}$ solution than for aluminas synthesized from the monomeric 
cation. The mean charge density of an aluminum atom within the Keggin polycation $(+7 / 13)$ is lower than within the monomeric species $(+3)$. Consequently, the global charge of the micelles must be adjusted to the charge of the $\mathrm{Al}_{13}$. This was realized by using a mixed micelle composed of 80 molar $\%$ of a negatively charged surfactant (sodium palmitate) and $20 \%$ of a positively charged surfactant (CTMABr). Moreover, interactions of $\mathrm{S}^{+} \mathrm{I}^{-}$type can be created between the cationic surfactant $\mathrm{S}^{+}$and the residual negative charges present at the alumina surface $\mathrm{I}^{-}$even below the isoelectric point.

The second way chosen (named way B) of synthesizing mesoporous aluminas was by acidification of a sodium aluminate solution whose $\mathrm{pH}$ was superior to 12 . In this case, the aluminum species were negatively charged. Consequently, we used a mixed micelle composed of 80 molar $\%$ of CTMABr and $20 \%$ of sodium palmitate. The synthesis temperature was $50^{\circ} \mathrm{C}$ for the two ways, value superior to the Krafft temperature of the surfactants, in order to dissolve them.

XRD results seem to indicate a better structuration of the aluminas synthesized by way A. Indeed, 3 diffraction peaks are recorded between $2 \theta=1$ and $10^{\circ}$ in this case (Fig. la). The mesostructure can be clearly indexed with a lamellar symmetry. On the contrary, no diffraction peaks are detected within the angular range $2 \theta=1$ and $10^{\circ}$ for sample $B$ (way B). The XRD pattern in the angular range $10^{\circ}<2 \theta<50^{\circ}$ indicates that samples obtained by way $\mathrm{A}$ have a bayerite $\left(\mathrm{Al}(\mathrm{OH})_{3}\right)$ structure and a broad peak at $2 \theta \approx 20^{\circ}$ seems to imply the presence of amorphous alumina case (Fig. 1 b). For sample $\mathrm{B}$, the presence of four broad peaks indicates a pseudo-boehmite $\left(\mathrm{AlOOH} \cdot \mathrm{nH}_{2} \mathrm{O}\right)$ structure. This difference of structure is confirmed by ${ }^{27} \mathrm{Al}$ MAS NMR experiments: aluminum atoms present tetrahedral and octahedral environments in samples A whereas only octahedral environments are detected in samples B. This latter observation is in good agreement with the spinel structure of pseudo-boehmite.

The better structuration of aluminas synthesized by way A is confirmed by chemical analysis. Indeed, the surfactants are incorporated within the final material with a molar ratio close to $0.12 \mathrm{CTMA}^{+}$and 0.33 palmitate anions per aluminum. In the materials synthesized by way $\mathrm{B}$, only $0.02 \mathrm{CTMA}^{+}$and 0.01 palmitate anions per aluminum are incorporated, which is consistent with the absence of a mesostructure. However, in all cases, only traces of bromide or sodium ions are detected. This indicates a direct interaction between the surfactants and the alumina framework in sample A, without any compensation ion.

All the materials (samples A and B) were calcined at $450^{\circ} \mathrm{C}$ in order to remove the surfactants. The resulting materials present no XRD peaks in the $2 \theta$ range between 1 and $10^{\circ}$. The mesostructure of sample A seems to collapse during the thermal treatment. All the samples have a XRD pattern characteristic of $\gamma$-alumina structure. In calcined sample B, aluminum atoms present tetrahedral and octahedral environments whereas pentrahedral environments are also present in the calcined sample A. They are probably due to the fixation of a water molecule on an aluminum atom (in a tetrahedral environment) present at the material surface.

The porosity features of the calcined materials were determined by nitrogen adsorption and desorption measurements. Figure 2 presents the isotherms of two materials synthesized by way A, obtained at a final pH of 6 (Fig. 2a) and 11 (Fig. 2b). They strongly depend on the final $\mathrm{pH}$ synthesis. Indeed, the material synthesized at $\mathrm{pH}=11$ presents a specific surface area much less important than the material synthesized at $\mathrm{pH}=6\left(530 \mathrm{vs} 950 \mathrm{~m}^{2} \cdot \mathrm{g}^{-1}\right)$ but a mean pore diameter larger (2.8vs less than $1.8 \mathrm{~nm}$, see Fig. 3). Consequently, a microporous solid is precipitated at low $\mathrm{pH}$ but it is possible to obtain a mesoporous material
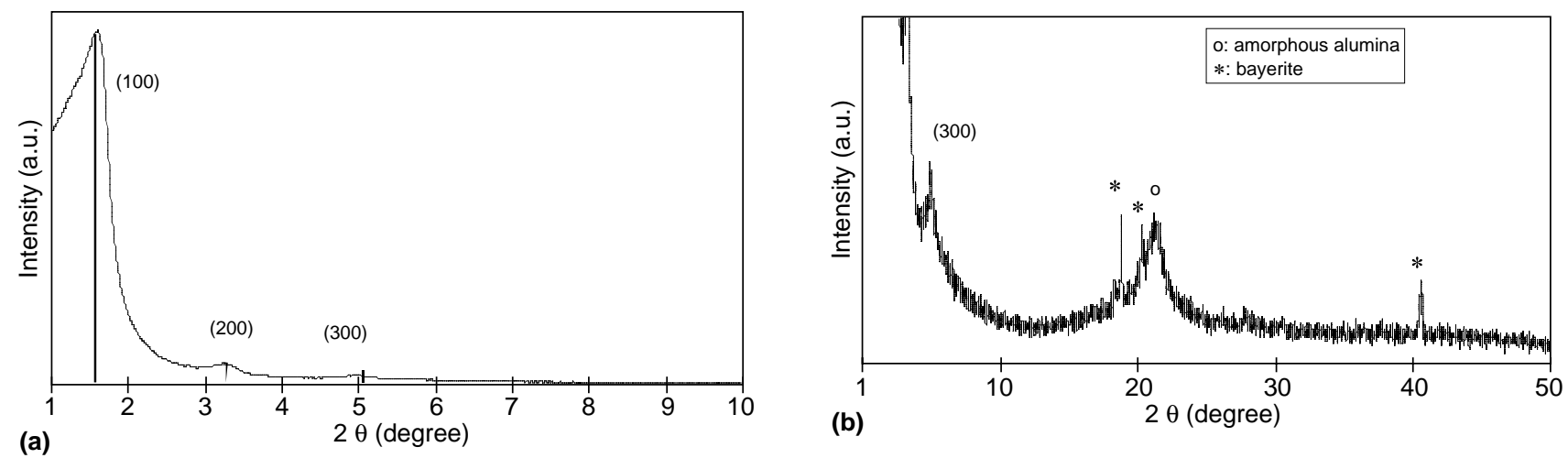

Figure 1

$\mathrm{X}$-ray powder diffraction patterns $\left(\mathrm{CuK}_{\alpha 1}\right.$ radiation) of the alumina synthesized by way $\mathrm{A}$ at $\mathrm{pH}=10$; a): for $1^{\circ}<2 \theta<10^{\circ}$; b): for $1^{\circ}<2 \theta<50^{\circ}$. 

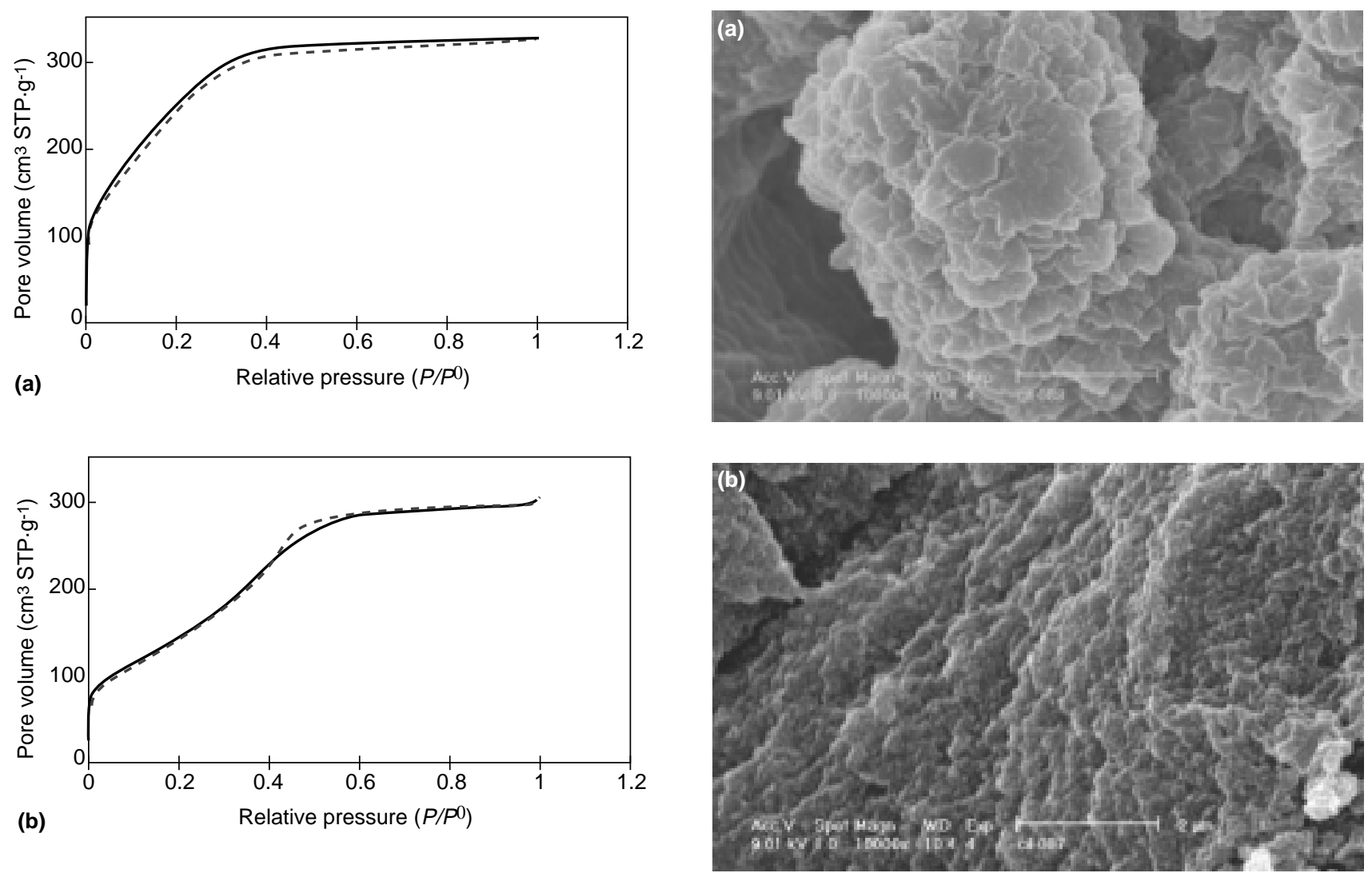

Figure 2

Nitrogen adsorption (-) and desorption (---) isotherms of samples synthesized by way $\mathrm{A}$; $\mathrm{a}$ ): at a final $\mathrm{pH}=6$; $\mathrm{b}$ ): at a final $\mathrm{pH}=11$.

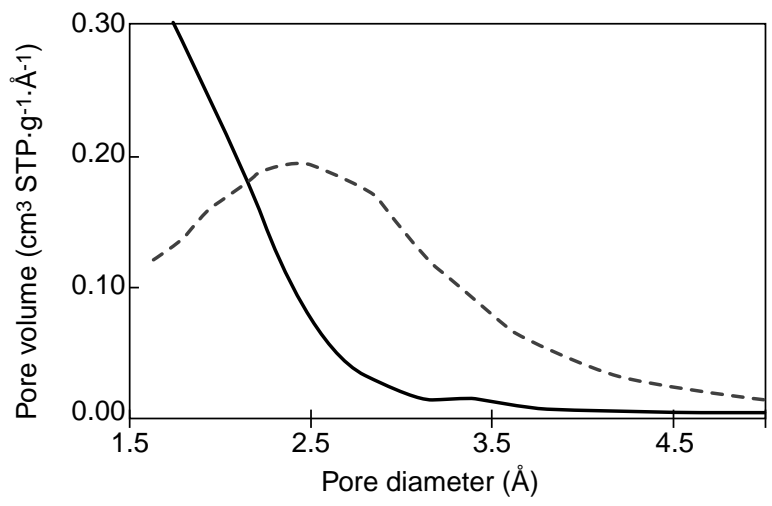

Figure 3

Pore size distributions, obtained from the adsorption branch, of the aluminas synthesized by way $\mathrm{A} ; \mathrm{a}$ ): at a final $\mathrm{pH}=6$ (-); b): at a final $\mathrm{pH}=11$ (---).

by increasing the final $\mathrm{pH}$. The morphologies of the samples are also different depending on the final $\mathrm{pH}$. Scanning electron micrographs of samples prepared at $\mathrm{pH}=5$ and 10 are given in Figure $4 \mathrm{a}$ and $4 \mathrm{~b}$, respectively. They show a

Figure 4

Scanning electron micrographs of samples synthesized by way $\mathrm{A}$; a): at a final $\mathrm{pH}=5$; $\mathrm{b}$ ): at a final $\mathrm{pH}=10$.

great difference in morphology: at $\mathrm{pH}=5$, the alumina platelets seems to be very plane whereas a granular morphology is observed for the material synthesized at a final $\mathrm{pH}$ of 10 . This leads us to think that the porosity would be due to the organization of the alumina particles which would differ with the charge of the aluminum species. Another explanation, similar to that put forward by Valange et al. [7], can be given for the difference in porosity: with increasing $\mathrm{pH}$, the charges of the aluminum species and thus the surfactant packing parameter, $g$, would decrease. Consequently, the inorganic sheets would ondulate. After calcination, the sheets would collapse on one another. However, the more ondulation, the bigger porosity.

Contrary to what was observed in way A, the porosity of the materials synthesized by way B and washed with water does not depend on the final $\mathrm{pH}$. Indeed, whatever the $\mathrm{pH}$ between 9.5 and 11.5, the nitrogen adsorption and desorption isotherms are similar to that presented in Figure 5. This isotherm is of type IV, characteristic of mesoporous materials. The solids obtained present a specific surface area of $400 \pm 50 \mathrm{~m}^{2} \cdot \mathrm{g}^{-1}$ and a pore volume of $0.5 \pm 0.1 \mathrm{~cm}^{3} \cdot \mathrm{g}^{-1}$. The scanning electron micrographs (see an example in 


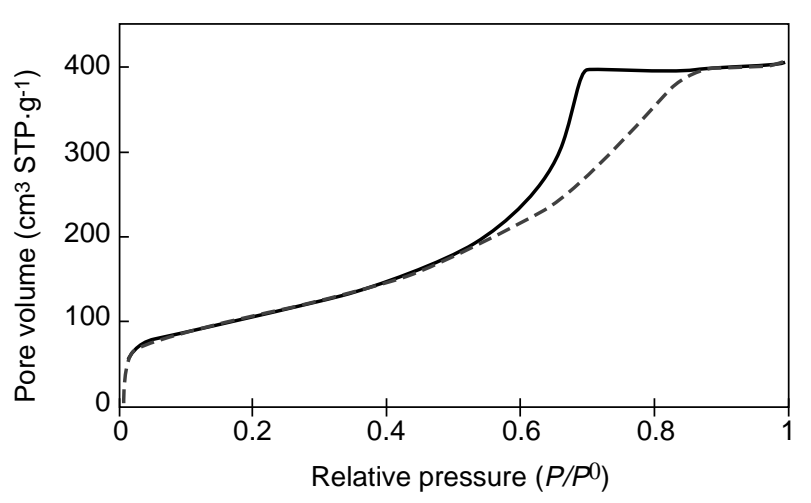

Figure 5

Nitrogen adsorption (-) and desorption (---) isotherms of a sample synthesized by way B and washed with water.



Figure 6

Scanning electron micrograph of a sample synthesized by way $\mathrm{B}$ and washed with water.

Figure 6) clearly show that the pores are created by the organization of the platelets of alumina (textural porosity). In order to optimize the synthesis procedure, the composition of the mixture was changed: the molar ratio CTMABr/sodium palmitate was made to vary between 2.3 and 8.0, the molar ratio of the global surfactants concentration per aluminum was also varied from 0 to 0.69 . Finally, the water content was doubled. However, all the materials obtained present the same characteristics in terms of porosity, XRD, chemical analysis and SEM. The addition order of the chemicals, the temperature, the aging time, the nature of the CTMA ${ }^{+}$counterion $\left(\mathrm{Br}^{-}\right.$or $\left.\mathrm{Cl}^{-}\right)$and the nature of the acid $\left(\mathrm{HCl}, \mathrm{HBr}, \mathrm{CH}_{3} \mathrm{CO}_{2} \mathrm{H}, \mathrm{H}_{3} \mathrm{BO}_{3}\right.$ ) have also no effect. It is important to recall that the porosity is textural and that the surfactants are not incorporated in the as-made material. Consequently, the nature of the solvent used to wash the sample can be of great importance. We chose to test two groups: aqueous and organic solvents. When washing with solvents from the first group (aqueous solutions of CTMABr and Triton X-100 or equivolumic mixture of water and ethanol), the porosity features are identical to the one obtained by washing with water only. On the contrary, washing with organic solvents (ethanol or acetone) gives very different results. A comparison of the adsorption isotherms of the samples washed with water, ethanol and acetone is presented in Figure 7. The difference of mesoporous volume is stricking: it is double for ethanol and acetone $\left(V_{p}=1.0 \mathrm{~cm}^{3} \cdot \mathrm{g}^{-1}\right)$ compared to water. The pore diameters and their distribution are also larger (pore diameters ranging from 2 to $30 \mathrm{~nm}$ ). The specific surface areas are close to $450 \pm 50 \mathrm{~m}^{2} \cdot \mathrm{g}^{-1}$ for these materials. The nitrogen isotherm of the solid washed with acetone (Fig. 7 (c)) is the only one which indicates the presence of macropores. These are created by the organization of particules whose diameter is between 100 to $700 \mathrm{~nm}$ as can be seen on the scanning electron micrograph presented in Figure 8. It is noteworthy that the visual aspect of the samples also differs: after washing with water or ethanol and drying, hard blocks are obtained. In the case of acetone, on the contrary, a white and dusty powder is recovered. The aggregation is reversible: washing with water and then with ethanol or acetone results in a pore volume similar to that obtained after washing with an organic solvent only. Similarly, washing with ethanol or acetone and then with water results in a pore volume similar to that obtained after washing with water only. From the previous observations (nature of the porosity and small amount of incorporated surfactants) can arise a question about the role of the surfactants. Consequently, syntheses were made in the absence of CTMABr and sodium palmitate. Whatever the washing solvent, the characteristics of the materials are similar to that observed in the presence of the surfactants. Therefore, the latter seems to have a negligible role.

The influence of the solvent used to wash can be explained in several ways. White et al. [32] already observed the importance of the solvent although they obtained solids with pore volume and specific surface areas less important than in our case: the values were $0.36 \mathrm{~cm}^{3} \cdot \mathrm{g}^{-1}$ and $353 \mathrm{~m}^{2} \cdot \mathrm{g}^{-1}$, respectively, for ethanol, $0.72 \mathrm{~cm}^{3} \cdot \mathrm{g}^{-1}$ and $302 \mathrm{~m}^{2} \cdot \mathrm{g}^{-1}$ for acetone, whereas they were equal to $0.34 \mathrm{~cm}^{3} \cdot \mathrm{g}^{-1}$ and $283 \mathrm{~m}^{2} \cdot \mathrm{g}^{-1}$ for water (the values of pore volumes were obtained by mercury intrusion for pore diameters between 3.6 and $100 \mathrm{~nm}$ ). The authors explained this phenomenon by the displacement of water by the two organic solvents which would entail a reduction of the surface tension and lower pore collapse during calcination. However, the phenomenon can also be explained by the higher vapor pressure for the organic solvents (ethanol and acetone) than for water which would lead to a higher network 


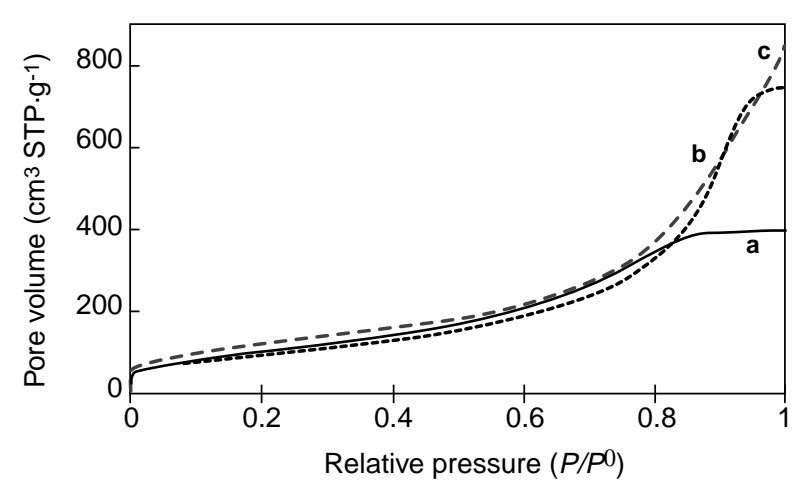

Figure 7

Nitrogen adsorption isotherms of samples synthesized by way B washed with water (a), ethanol (b), and acetone (c).

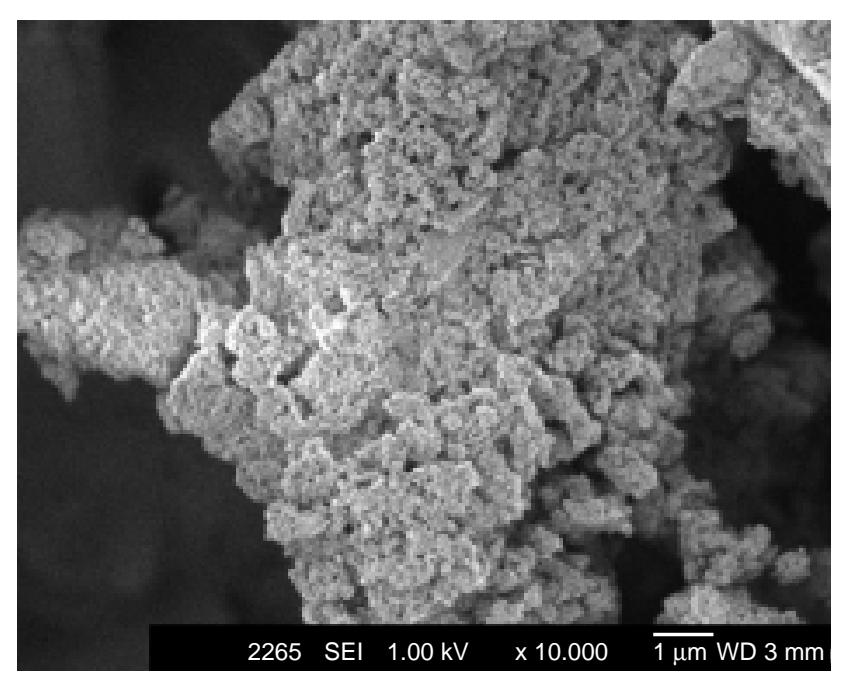

Figure 8

Scanning electron micrograph of a sample synthesized by way $\mathrm{B}$ and washed with acetone.

expansion and to the creation of larger pores. Moreover, the suspension obtained with water has an aspect similar to a gel. Consequently, the product recovered after drying would have a high density like a xerogel. Finally, a fourth explanation can be given. The $\mathrm{pH}$ of the suspension in water, measured during the last washing step, is close to the isoelectric point of alumina $(\mathrm{pH}=8-9)$. This significates that few charges are present at the particules surface, allowing the platelets to aggregate during washing. This explanation seems to be confirmed by a simple experiment: a sample was washed with water at a constant $\mathrm{pH}=10.5$. Pore volumes as high as $1.0 \mathrm{~cm}^{3} \cdot \mathrm{g}^{-1}$ were then observed. On the contrary, ethanol or acetone would create a repulsion among the particules.

\section{STUDY OF THE MECHANISM OF FORMATION OF A MESOSTRUCTURED ALUMINA}

The mechanism of formation of mesostructured or mesoporous aluminas has not been much studied yet. However, a better understanding of the fundamentals aspects of the syntheses would allow us to improve the procedures. We focused our study on a hexagonaly mesostructured alumina precipitated in the presence of SDS. The increase of the $\mathrm{pH}$ was realized by the slow decomposition of urea. The materials obtained at a final $\mathrm{pH}$ ranging between 6 and 7 all present the same characteristics. They present three XRD peaks between $2 \theta=1$ and $10^{\circ}$ which can be clearly indexed within the hexagonal symmetry with the (100), (110) and (200) indexes. This mesostructure is confirmed by transmission electron micrographs which show a honey comb network. As for the MCM-41 type material, they present a worm-like morphology. Dodecyl sulfate (which will be noted DS) is incorporated within the material with a molar ratio DS/Al close to 0.25 but no sodium atoms were detected, indicating a direct interaction between the surfactant and the inorganic framework. Moreover, urea was completely removed during washing as no nitrogen atoms were detected either. Finally, it is noteworthy that all the aluminum species react and precipitate as no aluminum atoms were found in the mother liquor. The material synthesized at $\mathrm{pH}=7$ described previously was calcined up to 450 and $600^{\circ} \mathrm{C}$. Even if the mesostructure has not completely collapsed (remanence of one XRD peak at $2 \theta$ $<10^{\circ}$ ), the calcined samples present type I-b "like" nitrogen isotherms (Fig. 9), characteristic of materials having large micropores (diameters between 1.5 and $2 \mathrm{~nm}$ ).

A study of the thermal decomposition of the surfactant occluded within the alumina framework was performed by sample controlled thermal analysis (SCTA) [26]. The aim

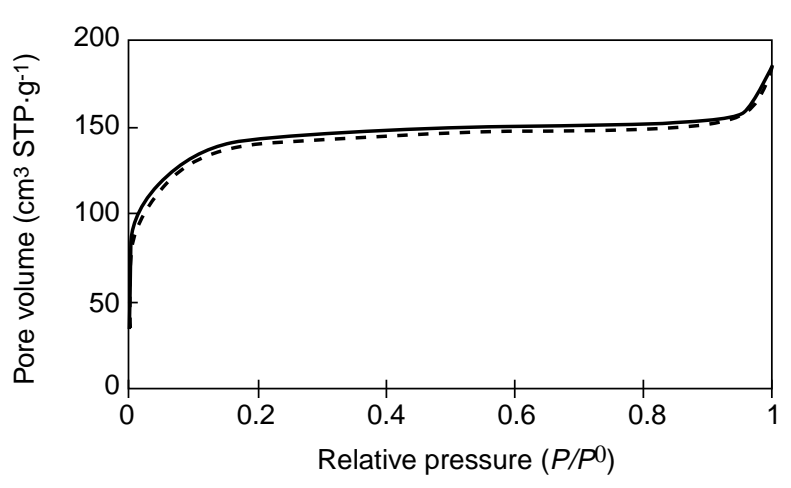

Figure 9

Nitrogen adsorption (-) and desorption (---) isotherms of the mesostrutured alumina synthesized in the presence of sodium dodecyl sulfate and calcined at $450^{\circ} \mathrm{C}$. 
was to characterize the nature of the interactions between the organic and the inorganic parts of the material and to try to liberate the mesoporosity. Figure 10 gives the SCTA curve of the mesostructured alumina and the main signals observed by mass spectrometry. The thermal analysis can be divided into three steps. At $100^{\circ} \mathrm{C}$, the signals at $m / z=18$ and 55 indicate the release of water and the decomposition of the alkyl chain, respectively. Between 400 and $550^{\circ} \mathrm{C}$, the sulfate headgroup is decomposed as shown by the signal at $\mathrm{m} / \mathrm{z}=64$. This experiment was compared to the SCTA of pure SDS (Fig. 11). In the latter case, the alkyl chain is decomposed at a higher temperature $\left(200^{\circ} \mathrm{C}\right)$ and the sulfate group at a lower temperature $\left(250^{\circ} \mathrm{C}\right)$ indicating a strong interaction between the sulfate head group and the alumina framework when the DS is occluded. This conclusion is similar to that obtained for lamellar aluminophosphates synthesized in the presence of mono- $n$ dodecyl phosphate [33-35]. Indeed, it was clearly showed that the phosphate head group of the surfactant was embedded within the alumina framework, leading to the formation of an aluminophosphate.

The SCTA technique permits also to calcine samples with few gradients of pressure and temperature. From the SCTA curve of the mesostructured alumina, four temperatures of calcination were selected. At $150^{\circ} \mathrm{C}$, during the decomposition of the alkyl chain, $250^{\circ} \mathrm{C}$, at the end of this step, $400^{\circ} \mathrm{C}$, when the sulfate group begin to decompose, and $580^{\circ} \mathrm{C}$, at the end of this latter step. Every XRD pattern present a single peak but the $d$ value and the intensity decrease with increasing temperature from $2.6 \mathrm{~nm}$ at $150^{\circ} \mathrm{C}$ to $1.8 \mathrm{~nm}$ at $580^{\circ} \mathrm{C}$. This is probably due to a shrinkage of the pore diameters and to a disorganization of the network. Transmission electron micrography confirms the disorganization of the structure. However, surprisingly, the wormlike morphology is not affected by the calcination. The porosity features of the samples were compared as can be seen in Figure 12. The pore volumes and specific surface areas increase when the calcination temperature goes from 150 up to $250^{\circ} \mathrm{C}$, which corresponds to the place left by the decomposition of the alkyl chain. They decrease with increasing temperature beyond $250^{\circ} \mathrm{C}$, confirming the strong interaction of the sulfate group of the surfactant and the alumina framework: the mesostructure collapses when trying to remove the sulfate.

The system described above is particularly well adapted for a study of the mechanisms of formation of organized mesostructured aluminas. Indeed, the material obtained present a hexagonal network. Moreover, the slow decomposition of urea allows to increase progressively the $\mathrm{pH}$. The species organize slowly and can be observed in situ in the clear precursor solution. Fluorescence techniques have revealed efficient as they permit to determine the size and the form of the micelles and to characterize their environment $[27,28]$. Indeed, the micelles form and size are deduced from the measurement, by time-resolved fluorescence quenching, of the aggregation numbers, $\mathrm{N}$, which represent the number of surfactant molecules per micelle. Besides, the exchange between two counterions, at the micelle surface, can be characterized by fluorescence lifetime measurements if one of the ions is a quencher of the probe fluorescence. Pyrene was introduced to serve as the probe molecule. For technical reasons and in order to slow down the process, the

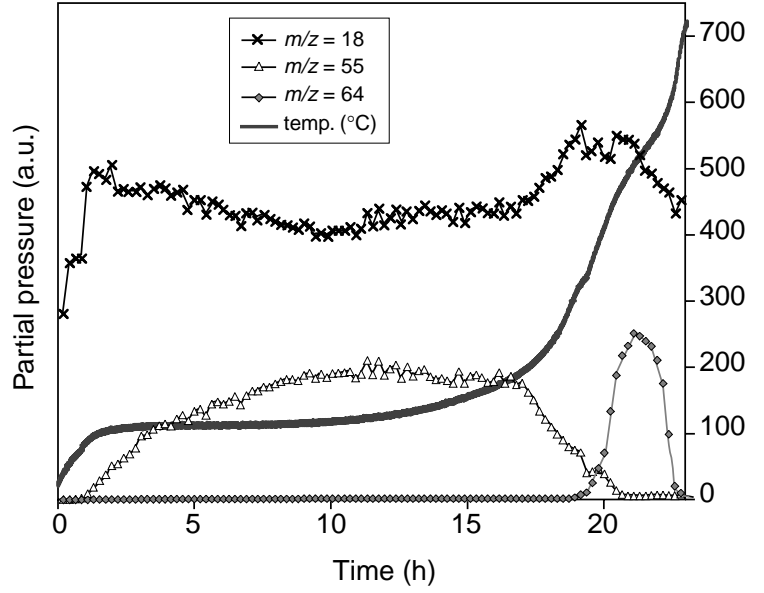

Figure 10

Sample controlled thermal analysis (SCTA) curve and main mass spectrometry signals of the hexagonal mesostrutured alumina synthesized in the presence of sodium dodecyl sulfate.

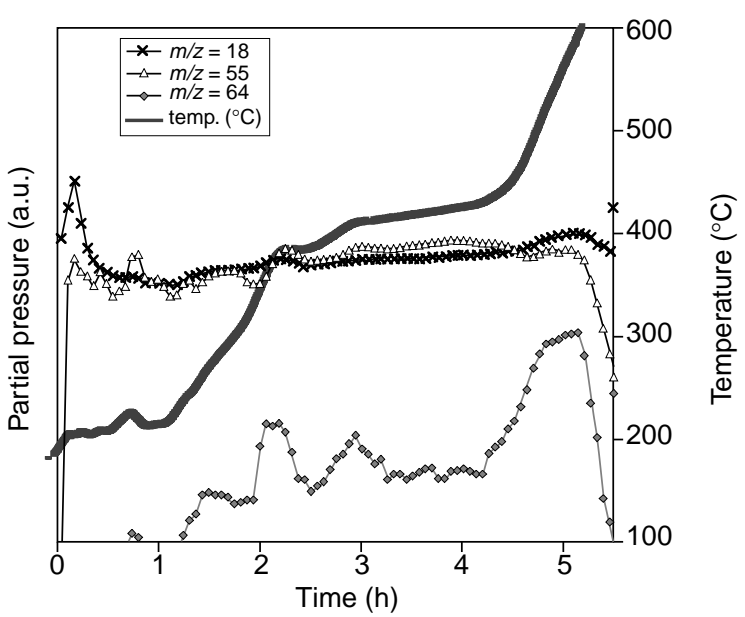

Figure 11

SCTA curve and main mass spectrometry signals of sodium dodecyl sulfate. 


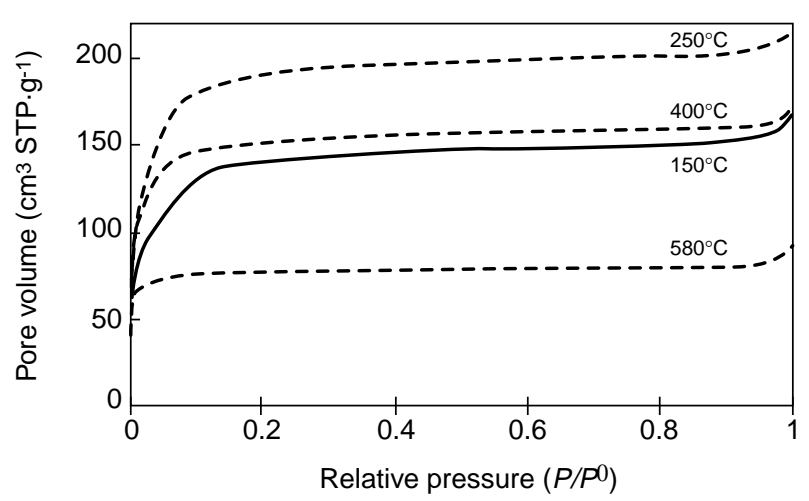

Figure 12

Nitrogen adsorption isotherms of the mesostructured alumina calcined by SCTA at $150,250,400$ and $580^{\circ} \mathrm{C}$.

temperature of the synthesis was dropped down to $60^{\circ} \mathrm{C}$. The time when the system reaches $60^{\circ} \mathrm{C}$ will be referred as the time $t=0$. The aggregation numbers and the fluorescence lifetimes $(\tau)$ of the pyrene in different systems are summarized in Table 1.

At $t=0$, in a $0.6 \mathrm{~mol} \cdot \mathrm{l}^{-1}$ aqueous solution of $\operatorname{SDS}$ at $60^{\circ} \mathrm{C}$, $N$ is equal to 74 , value which corresponds to quasi spherical micelles, and tis equal to $310 \mathrm{~ns}$ (see Table 1, line 1). When urea is added to the previous solution so as to have a urea concentration of $9.1 \mathrm{~mol} \cdot \mathrm{l}^{-1}, N$ decreases down to 53 and $\tau$ down to $280 \mathrm{~ns}$ (Table 1, line 2). Two mechanisms reported in the literature [36-45] can explain these results: either a direct mechanism which involves the penetration of urea molecules in the micelle palisade layer [36-42], either an indirect mechanism which suppose a modification of the chemical potential of the surfactant in the free state [43-45]. However, in view of the high concentration in urea, the direct mechanism is probably efficient in the system studied. Finally, the addition of aluminum nitrate, at a concentration of $0.3 \mathrm{~mol} \cdot \mathrm{l}^{-1}$, to the system SDS/urea leads to the precursor solution used to synthesized the mesostructured alumina. In this last solution, at $t=0, N$ is equal to 104 (Table 1, line 3) which corresponds to slightly elongated micelles with a axial ratio of about 1.8 [28]. The increase of $N$ with the addition of aluminum nitrate is due to the fact that anionic micelles bind multivalent cations more strongly than univalent cations [4648]. It was also observed that $\tau$ decreases with the addition of aluminum nitrate down to $176 \mathrm{~ns}$. In fact, the $1 / \tau$ value, at $t=0$, decreases in a linear way with the concentration of $\mathrm{Al}\left(\mathrm{NO}_{3}\right)_{3}$ (Table 1, lines 2-6). This is an indication of a quenching process. The aluminum species are not quenchers of the fluorescence of the pyrene. Consequently, the effect is probably due to the nitrate anions. The quenching effect of these ions was verified by replacing aluminum nitrate by aluminum chloride at the same concentration $\left(0.3 \mathrm{~mol} \cdot \mathrm{l}^{-1}\right)$. The $N$ values are similar in the two systems (compare lines 3 and 7 in Table 1), but $\tau$ is equal to $278 \mathrm{~ns}$ in the presence of aluminum chloride. Consequently, the addition of this chemical to a solution containing SDS and urea does not cause a decrease of $\tau$, contrary to what is observed with aluminum nitrate. This result confirms the quenching role of the nitrate species. Moreover, when the nitrate aluminum $\left(\mathrm{Al}\left(\mathrm{NO}_{3}\right)_{3}, 0.3 \mathrm{~mol} \cdot \mathrm{l}^{-1}\right)$ is replaced by sodium nitrate $\left(\mathrm{NaNO}_{3}, 0.9 \mathrm{~mol} \cdot \mathrm{l}^{-1}\right)$ in the precursor system so as to keep the nitrate concentration constant, $\tau$ is equal to $231 \mathrm{~ns}$ (Table 1, line 8), value much higher than the value obtained in the presence of $\mathrm{Al}\left(\mathrm{NO}_{3}\right)_{3}$. In this case, the quenching effect is very lightened. This implies that the nitrate anions are brought to the surface of the micelles by the aluminum cations, probably in order to compensate the excess of positive charges. In view of all the observations noted previously, the micelles in the precursor solution at $t=0$ are slightly elongated. They are surrounded by urea molecules and aluminum and nitrate ions.

The evolution of the micelle properties was then studied as a function of time. As a matter of comparison, the solutions of SDS and SDS/urea were characterized. However, neither the $N$ nor the $\tau$ values change during the experiment in these two solutions. In the precursor system, containing SDS, urea and aluminum nitrate, $N$ is constant as

\section{TABLE 1}

Aggregation numbers, $N$, and pyrene fluorescence lifetimes, $\tau$, in the systems studied at $60^{\circ} \mathrm{C}$ at time $t=0$

\begin{tabular}{l|l|c|c}
\hline & Composition & $N$ & $\tau(\mathrm{ns})$ \\
\hline 1 & SDS $\left(0.6 \mathrm{~mol} \cdot \mathrm{l}^{-1}\right)$ & 74 & 310 \\
2 & $\mathrm{SDS}\left(0.6 \mathrm{~mol} \cdot \mathrm{l}^{-1}\right) /$ urea $\left(9.1 \mathrm{~mol} \cdot \mathrm{l}^{-1}\right)$ & 53 & 280 \\
3 & $\mathrm{SDS}\left(0.6 \mathrm{~mol} \cdot \mathrm{l}^{-1}\right) /$ urea $\left(9.1 \mathrm{~mol} \cdot \mathrm{l}^{-1}\right) / \mathrm{Al}\left(\mathrm{NO}_{3}\right)_{3}\left(0.3 \mathrm{~mol} \cdot \mathrm{l}^{-1}\right)$ & 104 & 176 \\
4 & $\mathrm{SDS}\left(0.6 \mathrm{~mol} \cdot \mathrm{l}^{-1}\right) /$ urea $\left(9.1 \mathrm{~mol} \cdot \mathrm{l}^{-1}\right) / \mathrm{Al}_{\left(\mathrm{NO}_{3}\right)_{3}\left(0.08 \mathrm{~mol} \cdot \mathrm{l}^{-1}\right)}$ & - & 256 \\
5 & $\mathrm{SDS}\left(0.6 \mathrm{~mol} \cdot \mathrm{l}^{-1}\right) /$ urea $\left(9.1 \mathrm{~mol} \cdot \mathrm{l}^{-1}\right) / \mathrm{Al}\left(\mathrm{NO}_{3}\right)_{3}\left(0.15 \mathrm{~mol} \cdot \mathrm{l}^{-1}\right)$ & - & 211 \\
6 & $\mathrm{SDS}\left(0.6 \mathrm{~mol} \cdot \mathrm{l}^{-1}\right) /$ urea $\left(9.1 \mathrm{~mol} \cdot \mathrm{l}^{-1}\right) / \mathrm{Al}\left(\mathrm{NO}_{3}\right)_{3}\left(0.22 \mathrm{~mol} \cdot \mathrm{l}^{-1}\right)$ & - & 201 \\
7 & $\mathrm{SDS}\left(0.6 \mathrm{~mol} \cdot \mathrm{l}^{-1}\right) /$ urea $\left(9.1 \mathrm{~mol} \cdot \mathrm{l}^{-1}\right) / \mathrm{AlCl}_{3}\left(0.3 \mathrm{~mol} \cdot \mathrm{l}^{-1}\right)$ & 112 & 278 \\
8 & $\mathrm{SDS}\left(0.6 \mathrm{~mol} \cdot \mathrm{l}^{-1}\right) /$ urea $\left(9.1 \mathrm{~mol} \cdot \mathrm{l}^{-1}\right) / \mathrm{NaNO}_{3}\left(0.9 \mathrm{~mol} \cdot \mathrm{l}^{-1}\right)$ & - & 231 \\
\hline
\end{tabular}

-: nondetermined 
well until a precipitate is visually observed. On the contrary, $\tau$ increases in a linear way with time up to $208 \mathrm{~ns}$ at $t=40 \mathrm{~h}$ (vs $176 \mathrm{~ns}$ at $t=0$ ). This effect can only be attributed to a decrease of the concentration of the nitrate species at the micelle surface. Indeed, if it had been provoked by the departure of urea molecules from the micelle surface, one would have been expecting a modification of the micelle structure and an increase of $N$, which is not observed. Moreover, the quantity of urea molecules which are decomposed is too weak $(12.5 \mathrm{wt} \%)$ to explain the phenomenon. The departure of nitrate anions from the micelle palisade is certainly caused by a decrease of the positive charges (and consequently of the aluminum concentration) at the micelle surface, which can arise in two ways. On the one hand, the interfacial aluminum species can react with the hydroxyl ions produced by the decomposition of urea, leading to the formation of prepolymers. On the other hand, a part of the aluminum species can also leave the micelle surface to polymerize in the bulk and interact with SDS monomers. In this case, the micelles would serve only as reservoirs of monomers as was already described by Zana et al. in another paper on a silica-based mesoporous material [25]. However, as the addition of $\mathrm{Al}\left(\mathrm{NO}_{3}\right)_{3}$ to a solution containing SDS and urea leads to an increase in $N$, the departure of both aluminum and nitrate species from the micelle palisade should imply a decrease of the aggregation number which was not observed. Consequently, the first mechanism seem, at first sight, more realistic.

When considering the molar stoechiometry of the reactive medium ( $1 \mathrm{Al}\left(\mathrm{NO}_{3}\right)_{3}: 2$ SDS: 30 urea), only 1 SDS out of 6 is incorporated in the final material (the molar stoechiometry is $1 \mathrm{Al}: 0.3 \mathrm{SDS}$ ). One can reasonably assume that the effect on the aggregation number could have been averaged so that no change can be detected. Consequently, fluorescence measurements were also carried out on a solution containing SDS at a concentration of only $0.1 \mathrm{~mol} \cdot \mathrm{l}^{-1}$ i.e. 6 times less than the previous concentration. The results were very similar to that obtained with a SDS concentration of $0.6 \mathrm{~mol} \cdot \mathrm{l}^{-1}$ : the aggregation number was found constant with time $(N=95)$. In this case, every micelle would be surrounded by a sufficient number of aluminum atoms to see an impact on the micelle size if the species leave the micelle surface. As a consequence, we can exclude the mechanism considering the polymerization in the bulk and not on the micelles. Moreover, $\tau$ increases progressively from 164 to $170 \mathrm{~ns}$ and the precipitation occurs after $8 \mathrm{~h}$ only, whereas $40 \mathrm{~h}$ are necessary in the more concentrated system. The evolution of the time after which a precipitate is visually observed $\left(t_{\text {prec. }}\right)$ seems to confirm the polymerization of the aluminum species on the micelles. Indeed, in the two systems, containing SDS, urea and aluminum nitrate at a concentration of 0.6 and $0.1 \mathrm{~mol} \cdot \mathrm{l}^{-1}$, the concentration of urea is similar so the quantity of hydroxyl ions liberated is the same. But the concentration of aluminum species bound at the micelle surface decrease when decreasing the SDS concentration whereas the concentration of aluminum species in the bulk increases. In the case of a polymerization in the bulk, the hydroxyl ions would have to react with more free aluminum species as the SDS concentration decreases. So the polymerization would be slowed down and $t_{\text {prec. }}$ would increase, which is in opposition with the experimental result. On the contrary, in the case of a polymerization on the micelle surface, the hydroxyl ions would have to react with less micelle-bound aluminum species as the SDS concentration decreases. So the polymerization would be accelerated and $t_{\text {prec. }}$ would increase, which is effectively observed.

As a summary, the mechanism of formation of the mesostructured alumina (see the scheme presented in Figure 13) can be described as follows. In the initial solution $(t=0)$, the SDS micelles would be slightly elongated and surrounded by urea molecules, aluminum cations as well as nitrate anions. The nitrate ions have been proved to be fluorescence quenchers so that their presence, or absence, can be detected

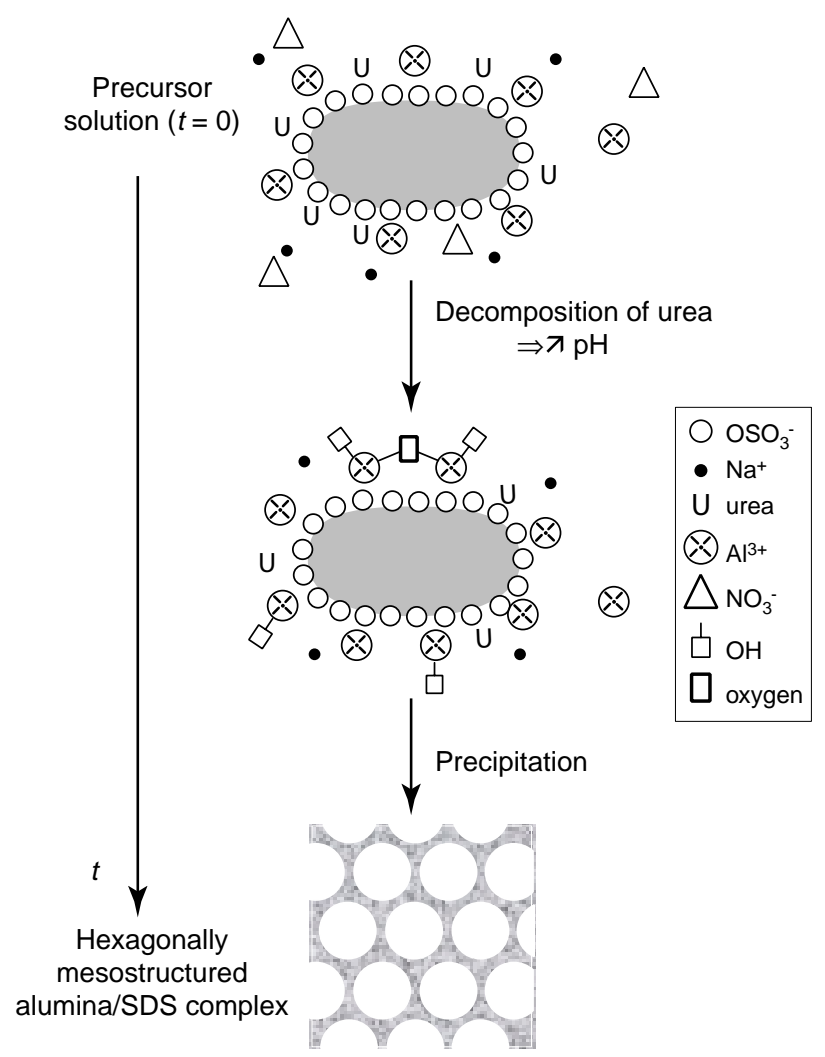

Figure 13

Scheme of the mechanism of formation of the mesostructured alumina synthesized in the presence of sodium dodecyl sulfate. 
through the variations of fluorescence lifetime. As the $\mathrm{pH}$ increases gradually from 3.5 to 5.5 by decomposition of urea, no change in micelle shape nor size is observed and no organization into a hexagonal array is detected. On the contrary, the fluorescence lifetime of the probe put up with time, showing a departure of nitrate anions which can be accounted for a polymerization of the aluminum species at the micelle surface.

\section{CONCLUSION}

Mesoporous aluminas were prepared from acidic and basic precursor solutions in the presence of mixed micelles composed of sodium palmitate and cetyltrimethylammonium bromide. It was observed a better structuration of the materials from the acidic medium. The lamellar structure obtained in this case collapses upon calcination but, at a high final $\mathrm{pH}(\mathrm{pH}=11)$, pore diameters of $2.8 \mathrm{~nm}$ could be obtained with a specific surface area of $530 \mathrm{~m}^{2} \cdot \mathrm{g}^{-1}$. From a basic medium, the surfactants are not essential to obtain a large porosity. A material having very good porous characteristics (specific surface area of $450 \mathrm{~m}^{2} \cdot \mathrm{g}^{-1}$ and pore volume of $1.0 \mathrm{~cm}^{3} \cdot \mathrm{g}^{-1}$ ) was obtained. They were obtained by washing with ethanol or acetone instead of water. These results were not observed before. Indeed, $\gamma$-alumina supports generally display a surface area ranging between 180 and $250 \mathrm{~m}^{2} / \mathrm{g}$ and a pore volume between 0.5 and $0.7 \mathrm{~cm}^{3} / \mathrm{g}$ $[1,2]$. However, the aluminas applications implies to shape the grains. The impact of this procedure on the material porosity has to be studied.

A fundamental study concerning the mechanism of formation of a hexagonally mesostructured alumina synthesized in the presence of sodium dodecylsulfate and urea was also carried out. It appeared that the surfactant could not be removed from the material without collapsing the hexagonal structure because the sulfate head group was too embedded within the alumina framework. Fluorescence measurements showed that urea, aluminum and nitrate species were in the micelle palisade layer in the precursor solution at the time $t=0$. When the $\mathrm{pH}$ increases, the aluminum species would polymerize at the micelle surface, inducing a decrease of the positive charges and thus the migration of nitrate anions into the bulk. This work constitutes the first attempt to elucidate the mechanism of formation of a mesoporous alumina.

\section{ACKNOWLEDGEMENTS}

We are thankful to Drs R. Zana and P.L. Llewellyn for their contribution to this work. These collaborations have been possible through the GDR 690 "FORMES". We are also thankful to $C N R S$ and IFP for financial support.

\section{REFERENCES}

1 Oberlander, R.K. (1984) Aluminas for Catalysts - Their Preparation and Properties. In: Applied Industrial Catalysis, 3, Leach, B.E., Academic Press, 63-113.

2 Brunelle, J.P., Nortier, P. and Poisson, R. (1987) In: Catalysts Supports and Supported Catalysts, Stiles, A.B., Butterworths Ed., 11-55.

3 Huo, Q., Margolese, D.I., Ciesla, U., Demuth, D.G., Feng, P., Gier, T.E., Sieger, P., Firouzi, A., Chmelka, B.F., Schüth, F. and Stucky, G.D. (1994) Organization of Organic Molecules with Inorganic Molecular Species into Nanocomposite Biphase Arrays. Chem. Mater., 6, 1176-1191.

4 Huo, Q., Margolese, D.I., Ciesla, U., Feng, P., Gier, T.E., Sieger, P., Leon, R., Petroff, P.M., Schüth, F. and Stucky, G.D. (1994) Generalized Synthesis of Periodic Surfactant/ Inorganic Composite Materials. Nature, 368, 317-321.

5 Vaudry, F., Khodabandeh, S. and Davis, M.E. (1996) Synthesis of Pure Alumina Mesoporous Materials. Chem. Mater., 8, 1451-1464.

6 Liu, X., Wei, Y., Jin, D. and Shih, W.H. (2000) Synthesis of Mesoporous Aluminum Oxide with Aluminum Alkoxide and Tartaric Acid. Mater. Lett., 42, 143-149.

7 Valange, S., Guth, J.L., Kolenda, F., Lacombe, S. and Gabelica, Z. (2000) Synthesis Strategies Leading to Surfactant-Assisted Aluminas with Controlled Mesoporosity in Aqueous Media. Microporous Mesoporous Mater., 35-36, 597-607.

8 Stein, A. and Holland, B.T. (1996) Aluminum-Containing Mesostructural Materials. J. Porous Mater., 3, 83-92.

9 Holland, B.T., Isbester, P.K., Munson, E.J. and Stein, A. (1999) Transformation of Layered Polyoxometallate Cluster Salts into Mesoporous Materials. Mater. Res. Bull., 34, 471482.

10 Yada, M., Machida, M. and Kijima, T. (1996) Synthesis and Deorganization of an Aluminium-Based Dodecyl Sulphate Mesophase with a Hexagonal Structure. Chem. Commun., 769-770.

11 Yada, M., Hiyoshi, H., Ohe, K., Machida, M. and Kijima, T. (1997) Synthesis of Aluminium-Based Surfactant Mesophases Morphologically Controlled Through a Layer to Hexagonal Transition. Inorg. Chem., 36, 5565-5569.

12 Yada, M., Hiyoshi, H., Machida, M. and Kijima, T. (1998) Aluminum-Based Surfactant Mesophases Structurally and Morphologically Controlled by Anions. J. Porous Mater., 5, 133-138.

13 Yada, M., Ohya, M., Machida, M. and Kijima, T. (1998) Synthesis of Porous Yttrium Aluminium Oxide Templated by Dodecyl Sulphate Assemblies. Chem. Commun., 1941-1942.

14 Yada, M., Kitamura, H., Machida, M. and Kijima, T. (1998) Yttrium-based Porous Materials Templated by Anionic Surfactant Assemblies. Inorg. Chem., 37, 6470-6475.

15 Yada, M., Kitamura, H., Machida, M. and Kijima, T. (1997) Biomimetic Surface Patterns of Layered Aluminium Oxide Mesophases Templated by Mixed Surfactant Assemblies. Langmuir, 13, 5252-5257.

16 Acosta, S., Ayral, A., Guizard, C. and Cot, L (1996) Synthesis of Alumina Gels in Amphiphilic Media. J. Sol-Gel Sci. Technol., 8, 195-199.

17 Cabrera, S., El Haskouri, J., Alamo, J., Beltrán, A., Beltrán, D., Mendioroz, S., Marcos, M.D. and Amorós, P. (1999) Surfactant-Assisted Synthesis of Mesoporous Alumina Showing Continuously Adjustable Pore Sizes. Adv. Mater., 5, 379-381. 
18 Cabrera, S., El Haskouri, J., Guillem, C., Latorre, J., BeltránPorter, A., Beltrán-Porter, D., Marcos, M.D. and Amorós, P. (2000) Generalised Syntheses of Ordered Mesoporous Oxides: the Atrane Route. Solid State Sci., 2, 405-420.

19 Bagshaw, S.A. and Pinnavaia, T.J. (1996) Mesoporous Alumina Molecular Sieves. Angew. Chem. Int. Ed. Engl., 10, 1102-1105.

20 Zhang, W. and Pinnavaia, T.J. (1998) Rare Earth Stabilization of Mesoporous Alumina Molecular Sieves Assembled Through an $\mathrm{N}^{0} \mathrm{I}^{0}$ Pathway. Chem. Commun., 1185-1186.

21 Yang, P., Zhao, D., Margolese, D.I., Chmelka, B.F. and Stucky, G.D. (1999) Block Copolymer Templating Syntheses of Mesoporous Metal Oxides with Large Ordering Lengths and Semicrystalline Framework. Chem. Mater., 10, 28132826.

22 Neeraj, M. and Eswaramoorthy, M. (1998) Mesoporous Alumina. Proc. Indian Acad. Sci., Chem. Sci., 2, 143-149.

23 Beck, J.S., Vartuli, J.C., Roth, W.J., Leonowicz, M.E., Kresge, C.T., Schmitt, K.D., Chu, C.T.W., Olson, D.H., Sheppard, E.W., McCullen, S.B., Higgins, J.B. and Schlenker J.L. (1992) A New Family of Mesoporous Molecular Sieves Prepared with Liquid Crystal Templates. J. Am. Chem. Soc., 114, 10834-10843.

24 Firouzi, A., Kumar, D., Bull, L.M., Besier, T., Sieger, P., Huo, Q., Walker, S.A., Zasadzinski, J.A., Glinka, C., Nicol, J., Margolese, D.I., Stucky, G.D. and Chmelka, B.F. (1995) Cooperative Organization of Inorganic-Surfactant and Biomimetic Assemblies. Science, 267, 1138-1143.

25 Zana, R., Frasch, J., Soulard, M., Lebeau, B. and Patarin, J. (1999) Fluorescence Probing Investigations of the Mechanism of Formation of Organized Mesoporous Silica. Langmuir, 15, 2603-2606.

26 Sicard, L., Llewellyn, P.L., Patarin, J. and Kolenda, F. (2001) Investigation of the Mechanism of the Surfactant Removal from a Mesoporous Alumina Prepared in the Presence of Sodium Deodecylsulfate. Microporous Mesoporous Mater., 44-45, 195-201.

27 Sicard, L., Frasch, J., Soulard, M., Lebeau, B., Patarin, J., Davey, T., Zana, R. and Kolenda, F. (2001) Investigations by Fluorescence Techniques of the Mechanism of Formation of Silica- and Alumina-Based MCM-41-type Materials. Microporous Mesoporous Mater., 44-45, 25-31.

28 Sicard, L., Lebeau, B., Patarin, J. and Zana, R. (2002) Study of the Mechanism of Formation of a Mesostructured Hexagonal Alumina by Means of Fluorescence Probing Techniques. Langmuir, 18, 74-82.

29 Brunauer, S., Emmet, P.H. and Teller, E. (1938) Adsorption of Gases in Multimolecular Layers. J. Am. Chem. Soc., 60 , 309-319.

30 Rouquerol, J., Bordère, S. and Rouquerol, F. (1992) Controlled Rate Evolved Gas Analysis. Recent Experimental Set-Up and Typical Results. Thermochim. Acta, 203, 193202.

31 Somasundaran, P., Huang, L. and Fan, A. (1999) In: Modern Characterization of Surfactant Systems, Surfactant Science Series, Binks, B.P. (Ed.), M. Dekker Inc., New York, 83, 213.

32 White, A., Walpole, A., Huang, Y. and Trimm, D.L. (1989) Control of Porosity and Surface Area in Alumina II. Alcohol and Glycol Additives. Appl. Catal., 56, 187-196.

33 Froba, M. and Tiemann, M. (1998) A New Role of the Surfactant in the Synthesis of Mesostructured Phases:
Dodecyl Phosphate as Template and Reactant for Aluminophosphates. Chem. Mater., 10, 3475-3483.

34 Tiemann, M., Fröba M., Rapp, G. and Funari, S.S. (2000) Nonaqueous Synthesis of Mesostructured Aluminophosphate/ Surfactant Composites: Synthesis, Characterization, and in situ SAXS studies. Chem. Mater., 12, 1342-1348.

35 Schulz, M., Tiemann, M., Froba, M. and Jager, C. (2000) NMR Characterization of Mesostructured Aluminophosphates. J. Phys. Chem. B., 104, 10473-10481.

36 Ruiz, C.C. (1999) Micelle Formation and Microenvironmental Properties of Sodium Dodecyl Sulfate in Aqueous Urea Solutions. Colloids Surfaces A., 147, 349-357.

37 Ruiz, C.C. (1995) A Photophysical Study of the Urea Effect on Micellar Properties of Sodium Dodecyl Sulfate Aqueous Solutions. Colloid Polym. Sci., 273, 1033-1040.

38 Abuin, E.B., Lissi, E.A., Aspee, A., Gonzalez, F.D. and Vara, J.M. (1997) Fluorescence of 8-anilinonaphthalene-1sulfonate and Properties of Sodium Dodecyl Sulfate Micelles in Water-Urea Mixtures. J. Colloid Interface Sci., 186, 332338.

39 Shen, X., Belletete, M. and Durocher, G. (1997) Studies of the Inclusion Complexation between a $3 \mathrm{H}$-Indole and $\beta$-Cyclodextrin in the Presence of Urea, Sodium Dodecyl Sulfate, and 1-Propanol. Langmuir, 22, 5830-5836.

40 Florenzano, F.H., Cardoso dos Santos, L.G., Cuccovia, I.M., Scarpa, M.V., Chaimovich, H. and Politi, M.J. (1996) UreaInduced Decrease of Anion Selectivity in Surfactant aggregates. Langmuir, 12, 1166-1171.

41 Asakawa, T., Hashikawa, M., Amada, K. and Miyagishi, S. (1995) Effect of Urea on Micelle Formation of Fluorocarbon Surfactants. Langmuir, 11, 2376-2379.

42 Hao, J.C., Wang, T.T., Shi, S., Lu, R.H. and Wang, H.Q. (1997) Electron Spin Resonance Study of Effect of Urea on Microenvironmental Properties of Alkylbenzene Sulfonate Micellar Solutions. Langmuir, 13, 1897-1900.

43 Manabe, M., Koda, M. and Shirihama, K. (1980) The Effect of 1-Alkanols on Ionization of Sodium Dodecyl Sulphate Micelles. J. Colloid Interface Sci., 77, 189-194.

44 Bonner, O.D., Bednarek, J.M. and Arisman, R.K. (1977) Heat Capacities of Urea and Water in Water and Dimetylformamide. J. Am. Chem. Soc., 99, 2898-2902.

45 MacDonald, J.C., Serphillips, J. and Guerrera, J.J. (1973) Effect of Urea Concentration Upon the Activation Parameters for Fluidity of Water. J. Phys. Chem., 77, 370-372.

46 Alargova, R.G., Petkov, D., Petsev, I., Broze, G. and Mehreteab, A. (1995) Light Scattering Study of Sodium Dodecyl Polyoxyethylene-2-Sulfonate Micelles in the Presence of Multivalent Counterions. Langmuir, 11, 15301536.

47 Baumueller, W., Hoffmann, H., Ulbricht, W., Tondre, C. and Zana, R. (1978) Chemical Relaxation and Equilibrium Studies of Aqueous Solutions of Lauryl Sulfate Micelles in the Presence of Divalent Metal Ions. J. Colloid Interface Sci., 64, 430-449.

48 Satake, I., Iwamatsu, I., Hosokawa, S. and Matuura, R. (1963) Surface Activities of Bivalent Metal Alkyl Sulfates (I) Micelles of Some Metal Alkyl Sulfates. Bull. Chem. Soc. Jap., 36, 204-209. 